\title{
Predictors of wanting to quit in a national sample of Aboriginal and Torres Strait Islander smokers
}

\begin{abstract}
$\mathrm{S}$ moking kills one in five Aboriginal and Torres Strait Islander people. ${ }^{1}$ Encouragingly, there was a steady decrease in the prevalence of daily smoking in the decade to 2012-2013, from $49 \%$ to $42 \%$ in those aged 15 years or older. ${ }^{2}$ The 2008 National Aboriginal and Torres Strait Islander Social Survey (NATSISS) found that $62 \%$ of smokers had either cut down or attempted to quit smoking in the previous year, ${ }^{3}$ indicating high levels of motivation to quit.
\end{abstract}

However, smoking in remote areas has not declined to the same degree as in other areas, and the difference between smoking rates of Aboriginal and Torres Strait Islander peoples and non-Indigenous Australians has not diminished. ${ }^{4}$ Factors reported to contribute to the high prevalence of smoking among Aboriginal and Torres Strait Islander peoples include ongoing effects of colonisation and dispossession, normalisation of smoking, socioeconomic inequalities and a lack of access to services that support quitting. ${ }^{5-9}$ Smoking has also been associated with high rates of psychological distress, experiences of racism and binge drinking among Aboriginal and Torres Strait Islander peoples. ${ }^{10,11}$ Where and how these factors influence the pathway to smoking and quitting has important implications for tobacco control interventions. ${ }^{12}$

While there has been limited evaluation of strategies to reduce smoking among Aboriginal and Torres Strait Islander peoples, there is some evidence that health professional advice and advertising campaigns increase interest in quitting. ${ }^{13,14}$ Here, we explore which policies and other factors predict wanting to quit in a national sample of Aboriginal and Torres Strait Islander smokers.

\section{Methods}

\section{Survey design and participants}

The Talking About The Smokes (TATS) project surveyed 1643 current smokers

\section{Abstract}

Objective: To describe factors that predict wanting to quit smoking in a national sample of Aboriginal and Torres Strait Islander people.

Design, setting and participants: The Talking About The Smokes (TATS) project used a quota sampling design to recruit participants from communities served by 34 Aboriginal community-controlled health services and one community in the Torres Strait. Baseline survey data were collected from 1643 current smokers between April 2012 and October 2013.

Main outcome measure: Wanting to quit smoking.

Results: More than two-thirds of smokers (70\%) said they want to quit. Many factors were associated with wanting to quit, including past quitting activity. Interest in quitting was lower among men and smokers from economically disadvantaged areas, but there was no difference by age, remoteness or other measures of economic disadvantage. Attitudes and beliefs negatively associated with wanting to quit included enjoying smoking and believing quitting to be very difficult, and those positively associated included regretting ever starting to smoke, perceiving that local Aboriginal and Torres Strait Islander community leaders disapprove of smoking, believing non-smokers set a good example to children, worrying about future smoking-related health effects and believing quitting to be beneficial. Reporting support from family and friends was predictive of wanting to quit, but factors related to smoking in the social network were not. Associations with health and wellbeing were mixed. While most tobacco control policy exposure variables were positively associated with wanting to quit, two - receiving advice to quit from a health professional, and recall of targeted anti-tobacco advertising - appeared to have an effect that extended beyond influencing relevant attitudes and beliefs.

Conclusion: Interest in quitting among Aboriginal and Torres Strait Islander smokers appears to be influenced by a broad range of factors, highlighting the importance of taking a comprehensive approach to tobacco control. Advice from health professionals and targeted advertising appear to be important intervention strategies.

from April 2012 to October 2013 (Wave 1 , or baseline). The survey design and participants have been described in detail elsewhere. ${ }^{15,16}$ Briefly, the study used a quota sampling design to recruit participants from communities served by 34 Aboriginal communitycontrolled health services (ACCHSs) and one community in the Torres Strait. Project sites were selected based on the population distribution of Aboriginal and Torres Strait Islander people by state or territory and remoteness. In most sites (30/35), we aimed to interview a sample of 50 smokers or recent quitters (ex-smokers who had quit $\leqslant 12$ months before), with equal numbers of men and women and those aged 18-34 and $\geqslant 35$ years. The sample sizes were doubled in four large city sites and the Torres Strait community. People were excluded if they did not identify as
Aboriginal or Torres Strait Islander, were less than 18 years old, were not usual residents of the area, were staff of the ACCHS or were deemed unable to consent or complete the survey.

In each site, different locally determined methods were used to collect a representative, albeit non-random, sample. The baseline sample closely matched the sample distribution of the 2008 NATSISS by age, sex, jurisdiction and remoteness, and number of cigarettes smoked per day for current daily smokers. However, there were inconsistent differences in some socioeconomic indicators: our sample had higher proportions of unemployed people, but also higher proportions who had completed Year 12 and who lived in more advantaged areas. ${ }^{15}$

Interviews were conducted face to face by trained interviewers, almost 
1 Hierarchical model for multivariable analysis

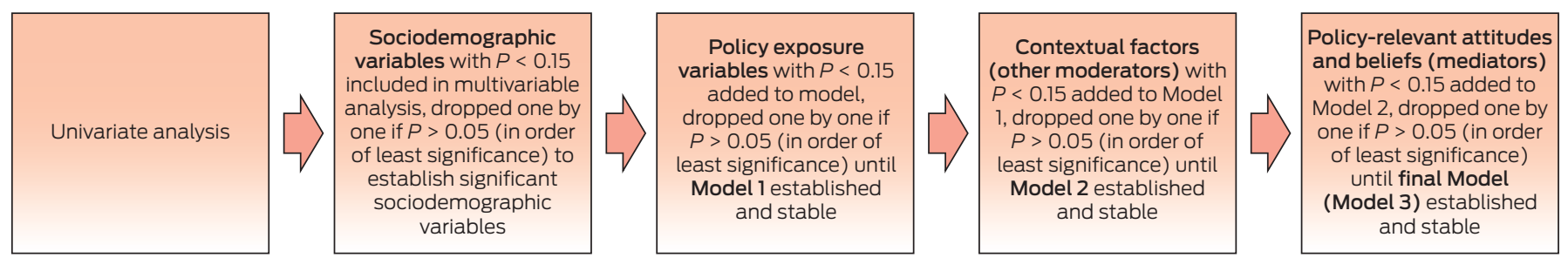

all of whom were members of the local Aboriginal and Torres Strait Islander community. The survey, entered directly onto a computer tablet, took 30-60 minutes to complete. A single survey of health service activities was also completed for each site.

The project was approved by three Aboriginal human research ethics committees (HRECs) and two HRECs with Aboriginal subcommittees: Aboriginal Health \& Medical Research Council Ethics Committee, Sydney; Aboriginal Health Research Ethics Committee, Adelaide; Central Australian HREC, Alice Springs; HREC for the Northern Territory Department of Health and Menzies School of Health Research, Darwin; and the Western Australian Aboriginal Health Ethics Committee, Perth.

\section{Main outcome measure}

All smokers were asked "Do you want to quit smoking?" ("yes", "no" or "don't know"). This outcome was dichotomised for logistic regression analyses, with "don't know" responses excluded. Those who reported wanting to quit were also asked how much they want to quit ("a little", "somewhat" or "a lot").

\section{Predictors of wanting to quit}

Predictors of wanting to quit were explored for key sociodemographic indicators, known predictors of smoking and quitting, and policy exposure variables. These questions, and how they have been grouped for multivariable analyses, are summarised in Appendix 1.

\section{Statistical analyses}

All analyses were performed using Stata, version 13.1 (StataCorp). Stata's survey [SVY] commands were used to adjust for the sampling design, identifying the 35 project sites as clusters, and the quotas based on age, sex and smoking status as strata. ${ }^{17}$ The relationship between wanting to quit and each predictor variable (Appendix 1) was explored using logistic regression. Variables with two or more categories were then collapsed based on previously established cut-points or those that best fitted the data and context. With the exception of the quitting history subset, which was not included in the multivariable model, variables of importance (with $P<0.15$ on adjusted Wald tests) were added hierarchically, commencing with the sociodemographic factors (Box 1). Measures of past quitting activity were not included in the multivariable models because they are indicators of past motivation to quit, which may confound analyses about present intentions. A backwards elimination technique was used to arrive at each model.

Less than $1 \%$ of smokers (11/1643) did not respond to the question on wanting to quit and were excluded from all analyses. Of the remainder, data for the $4.8 \%$ of smokers $(79 / 1632)$ who did not know if they wanted to quit were also excluded, leaving 1553 smokers for analysis. While those who declined to respond to questions on predictor variables $(\leqslant 34 / 1553)$ were also excluded from relevant analyses, all "don't know" responses for these variables were combined with other categories as best fitted the data, for a more complete representation of our smoker sample (Appendix 2).

\section{Results}

Of the 1553 smokers, 1083 (70\%) reported wanting to quit. Of these, $9 \%$ (100/1079) wanted to quit "a little",
$31 \%(330 / 1079)$ said "somewhat" and $60 \%(649 / 1079)$ wanted to quit "a lot".

Many of the 56 predictor variables (Appendix 1) were associated with wanting to quit; those that were not are listed in Appendix 3. Variables that were significant predictors in at least one multivariable model are included in Box 2. Those that only held significant univariate associations are listed in Appendix 4, along with variables for quitting history. Measures of past quitting activity were consistently associated with wanting to quit on univariate analysis, which demonstrates convergent validity.

There were no differences in wanting to quit by age or remoteness (Appendix 3). However, men were less likely than women to want to quit (63\% v $76 \%$ ). While those from areas of greater disadvantage were less likely to want to quit (Box 2), other measures of economic advantage (such as education and employment) did not predict interest in quitting in any of the multivariable models (Appendix 4).

Smokers who said they enjoyed smoking and that smoking is an important part of life were less likely to want to quit (Appendix 4), although only enjoying smoking significantly predicted lack of interest in quitting in the final model (Model 3) (Box 2). Agreement with each of the statements regarding the negative aspects of smoking was associated with increased interest in quitting in unadjusted analyses (Appendix 4). When controlling for other factors (Model 3, Box 2), wanting to quit was higher among those who regretted ever starting to smoke, were very worried about the future effects of smoking on their health, 
2 Hierarchical model of associations with wanting to quit in a national sample of Aboriginal and Torres Strait Islander smokers*

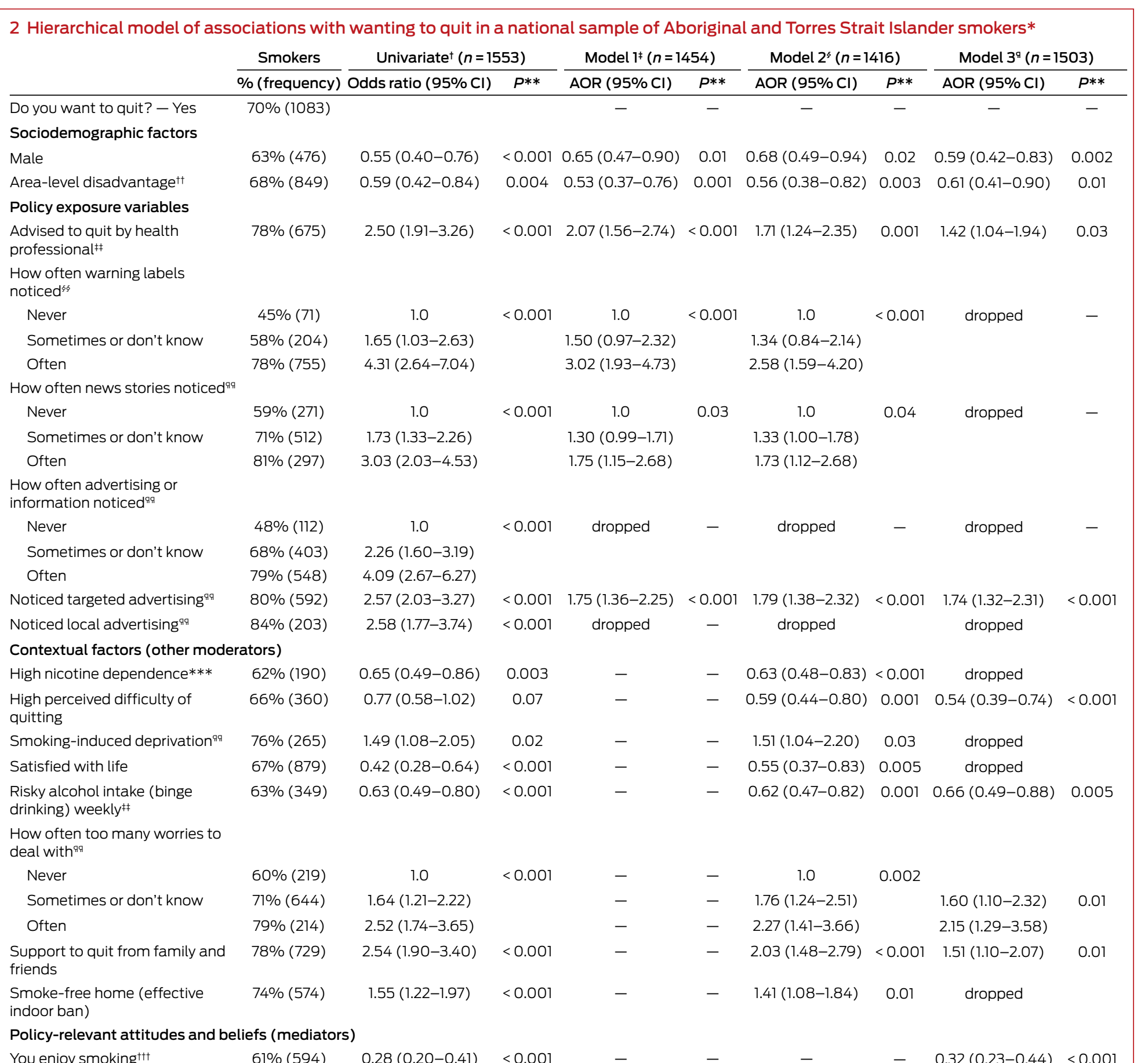

drinking) weekly

How often too many worries to deal with

Never
Sometimes or don't know
Often

Support to quit from family and friends

Smoke-free home (effective indoor ban)

Policy-relevant attitudes and beliefs (mediators)

You enjoy smoking ${ }^{\dagger \dagger}$

If you had to do it over again,

you would not have started

smoking ${ }^{\dagger \dagger}$

Community leaders where you live disapprove of smoking ${ }^{\dagger \dagger}$

Being a non-smoker sets a good example to children ${ }^{\dagger+\dagger}$

Very worried about future health effects

High perceived benefit from quitting

\section{$60 \%(219)$ \\ $79 \%(214)$}

1.0

$1.64(1.21-2.22)$

$2.52(1.74-3.65)$

$2.54(1.90-3.40)$

1.55 (1.22-1.97)
$<0.001$

$-$

-

$-$

$-$

-

$<0.001$
61\% (594)
$75 \%(907)$

$0.28(0.20-0.41)<0.001$

$2.79(1.96-3.97)<0.001$

$77 \%(504)$

73\% (1029)

90\% (500)

$82 \%(780)$
$1.89(1.47-2.43)<0.001$

$4.64(2.91-7.38)<0.001$

$6.20(4.44-8.65)<0.001$

$4.42(3.25-6.00)<0.001$ $-\quad 1.0$

- $\quad 1.76(1.24-2.51)$

- $2.27(1.41-3.66)$

$-$

$2.03(1.48-2.79)$

- $\quad 1.41(1.08-1.84)$

0.01

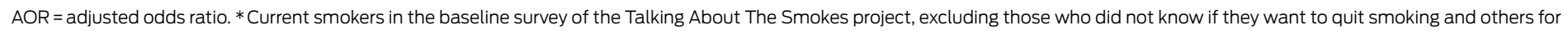

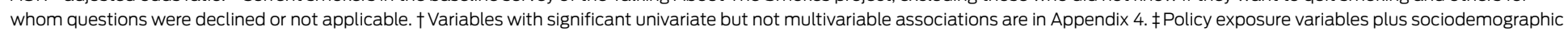

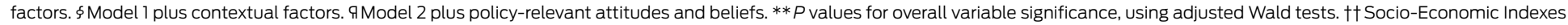

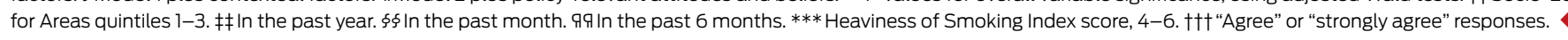


and believed quitting would be beneficial. Believing that not smoking sets a good example to children and perceiving that local Aboriginal and Torres Strait Islander community leaders disapprove of smoking also predicted wanting to quit in multivariable modelling, but perceiving disapproval of smoking by mainstream society did not.

More non-daily smokers than daily smokers said they want to quit $(78 \%$ v 68\%). Those assessed as highly nicotine-dependent (based on the Heaviness of Smoking Index) were less likely to want to quit, compared with those who were less dependent (Model 2, Box 2). While a perception that quitting would be very difficult reduced the odds of wanting to quit, even when controlling for relevant attitudes (Model 3, Box 2), reporting strong urges or cravings did not (Appendix 3). Smokers who consumed risky levels of alcohol at least weekly were also less likely to want to quit. On the other hand, smokers who experienced too many worries or went without food or other essentials (because of money spent on cigarettes) were more likely to want to quit, although only having too many worries was predictive in the final model (Box 2).

Very few contextual factors relating to the social environment predicted wanting to quit, and only support from family and friends remained in the final model. Smoke-free environments were also associated with interest in quitting: home (but not workplace) smoking bans predicted wanting to quit when adjusting for sociodemographic factors (Model 2, Box 2), but not when relevant attitudes were considered (Model 3).

All variables relating to exposure to tobacco control policies were positively associated with wanting to quit, except for the presence of dedicated tobacco control staff or resources at the local health service (determined from the project site survey). Only two policy exposure variables appeared to have relationships that were not fully explained (mediated) by relevant attitudes and beliefs: these were having received advice to quit from a health professional in the past year, and having noticed targeted anti-tobacco advertising in the past 6 months.

\section{Discussion}

It is encouraging that most Aboriginal and Torres Strait Islander smokers said they want to quit, similar to past studies. ${ }^{6,13,18}$ We found that a broad range of factors were associated with wanting to quit, including attitudes towards smoking, social normative beliefs, dependence-related measures, other contextual factors and exposure to a range of tobacco control interventions. The diversity of influences highlights the importance of taking a comprehensive approach to tobacco control, through strategies that target the individual, the community and broader aspects of society and the environment.

It is of particular importance that many of the tobacco control strategies assessed were associated with wanting to quit. While it is possible (as with all cross-sectional associations) that wanting to quit led to heightened attention to materials or programs about smoking, these relationships remained significant whether or not other strategies were also noticed. There would seem to be little doubt that the tobacco control strategies assessed were contributing to interest in quitting. In particular, being advised to quit smoking by a health professional and recalling targeted anti-tobacco advertising were predictive of wanting to quit, and these relationships were not contingent on forming relevant attitudes and beliefs. That is, if a health professional says "you should quit smoking", people become more motivated to do so, even if their beliefs about smoking (eg, whether they will benefit from quitting) remain unchanged. This suggests that these interventions have some direct influence on interest in quitting, whether or not they also influence other beliefs. This motivational effect of brief advice is consistent with past findings, ${ }^{13,19}$ including in other populations, ${ }^{20}$ and should affirm the importance of such conversations for health professionals.
While there are mixed findings regarding the effect of media campaigns on quit intentions, there is good evidence that well funded mass media campaigns promote quitting. ${ }^{21}$ Our results suggest that targeted messages have added potency for Aboriginal and Torres Strait Islander peoples, beyond that of mainstream mass media messages, which are thought to be equally effective for Indigenous peoples as for the general population. ${ }^{14}$ The added potency of targeted and local advertising may be due to greater cultural relevance, ${ }^{14,22,23}$ or because of community involvement and leadership in its development. For example, ACCHSs often use targeted advertising and information that may incorporate Aboriginal and Torres Strait Islander cultural beliefs, holistic wellbeing, family messages, storytelling, role modelling and community elders. ${ }^{24}$ In general, targeted messages are indicated where beliefs and sources of motivation differ from those in the general population. ${ }^{25}$ Elsewhere in this supplement, we report that beliefs about harm to others appear particularly motivating, ${ }^{26}$ and that smokers who recalled more targeted or local targeted advertising were more likely to hold these beliefs. ${ }^{27}$

Our results emphasise previous findings regarding the power of others to motivate quitting. ${ }^{7,19,26,28,29}$ Similar findings have been reported for other indigenous populations. ${ }^{30-32}$ In this regard, it is relevant that having more friends and family members who smoke did not reduce interest in quitting in our sample, consistent with previous findings. ${ }^{13}$ That said, social networks may be more important in making and sustaining quit attempts, as reported elsewhere. ${ }^{33,34}$

Our finding that fewer men wanted to quit is cause for concern, particularly when interpreted alongside findings elsewhere in this supplement that fewer men are making quit attempts. ${ }^{35}$ Sex was not found to predict wanting to quit in a similar but smaller study conducted in regional New South Wales. ${ }^{13}$ Further, national surveys have not shown large differences between the sexes in the decline of smoking uptake or the rise of successful quitting among Aboriginal 
and Torres Strait Islander peoples. ${ }^{36}$ International literature shows the relationship between sex and quitting is complex and appears to differ according to age, social standing and other factors such as differential use of stop-smoking medications, ${ }^{37,38}$ which we have not explored here.

In contrast to the general population, where younger, economically advantaged smokers report greater interest in quitting, ${ }^{39,40}$ wanting to quit was not predicted by age, remoteness, education or employment in our results, despite evidence of smaller reductions in smoking among those in remote areas and older age groups. ${ }^{2}$ This suggests differences in smoking prevalence may be due to the challenges of quitting successfully for these smokers, not lack of motivation.

Similarly, past research shows that smokers who experience mental ill health are no less interested in quitting, consistent with our findings for smokers who reported having too many worries or feeling depressed. .1-43 $^{43}$ However, these people are less likely to succeed, particularly if they are economically disadvantaged. ${ }^{41-43}$ The solution for these smokers extends beyond building motivation to quit. In other settings of disadvantage, a combination of short-term strategies, which deal with immediate challenges to quitting, and longer-term policy interventions, which tackle factors that cause disadvantage and marginalisation, is recommended. ${ }^{44}$ These recommendations are consistent with taking a comprehensive approach to tobacco control.

\section{Strengths and limitations}

The TATS project sample was broadly representative of the Aboriginal and Torres Strait Islander population, albeit with some inconsistent sociodemographic differences when compared with the 2008 NATSISS sample. It is possible that a bias towards those who were more connected to the local health service boosted levels of exposure to policies or programs such as brief intervention or use of local educational materials, which may have inflated our estimates of these exposures. However, comparisons between the TATS project and the 2008 NATSISS show that similar proportions of smokers had seen a health professional in the previous year and had attempted to quit in the previous year, ${ }^{15}$ which reassures us that there was not strong systematic bias caused by recruitment by health service staff.

While interviewer-assisted surveys could lead to a social desirability bias towards wanting to quit, evidence from elsewhere suggests that respondents are equally or less likely to say they want to quit in interviewer-assisted telephone surveys compared with postal or online surveys. ${ }^{45,46}$ Social desirability biases can also be culturally moderated, which we sought to overcome by engaging local interviewers to reduce the social distance between the interviewer and participant. ${ }^{47}$ Given there was no evidence of any strong or systematic bias, we believe it appropriate to compare our estimates and cross-sectional associations with other surveys and to generalise our findings to the national Aboriginal and Torres Strait Islander population. ${ }^{15}$

While we excluded $4.8 \%$ of smokers who did not know if they want to quit (to better predict wanting to quit, as a dichotomous outcome), the demographic characteristics of these smokers were similar to those who were included in our analyses.

Using a hierarchical approach for the multivariable analysis allowed us to determine the degree to which policy exposures could be accounted for by relevant attitudes and beliefs (ie, those that precede wanting to quit). The hierarchical model unmasks policy exposure variables that have influenced wanting to quit by strengthening relevant attitudes and beliefs on the pathway to quitting. It is likely that we have not measured all attitudes and beliefs that are influenced by the tobacco control interventions assessed, which may explain why some interventions remained in the final model (ie, appearing to exert a direct effect on wanting to quit). However, although not exhaustive, the variables included in the multivariable modelling have been shown in other articles in this supplement to be relevant and important, and have also been shown to be relevant to a diverse range of societies and tobacco control environments. ${ }^{47}$ Further, the strong relationships between wanting to quit and past quitting activity mirror findings from other populations, which demonstrate that repeated (and failed) attempts to quit are common among those who are most interested in quitting. ${ }^{48,49}$ This validates the question "Do you want to quit?" as an indicator of interest in quitting among Aboriginal and Torres Strait Islander peoples.

It is important to remember that some of the predictors of wanting to quit are likely to be caused by wanting to quit. Further, at least for the general population, determinants of success once a quit attempt is initiated are quite different to those for wanting and attempting to quit. ${ }^{48,50,51}$ Some of the variables that were unrelated to interest in quitting among Aboriginal and Torres Strait Islander smokers are likely to predict quit success. Longitudinal research is needed to assess how factors associated with wanting to quit influence the pathway to making and sustaining quit attempts.

With these considerations in mind, it is clear that most Aboriginal and Torres Strait Islander smokers want to quit. The broad range of factors associated with wanting to quit highlight the importance of taking a comprehensive approach to tobacco control. While it is likely that a continuation of the strategies already in use will enable high levels of motivation to be maintained, the next challenge will be to translate this into more successful quitting.

Acknowledgements: The full list of acknowledgements is available in Appendix 5.

Competing interests: No relevant disclosures.

Provenance: Not commissioned; externally peer reviewed.

Received 17 Feb 2015, accepted 11 May 2015.

1 Vos T, Barker B, Begg S, et al. Burden of disease and injury in Aboriginal and Torres Strait Islander Peoples: the Indigenous health gap. Int J Epidemiol 2009; 38: 470-477.

2 Australian Bureau of Statistics. Australian Aboriginal and Torres Strait Islander Health Survey: updated results, 2012-13. 
Canberra: ABS, 2014. (ABS Cat. No. 4727.0.55.006.)

3 Australian Bureau of Statistics. The health and welfare of Australia's Aboriginal and Torres Strait Islander peoples, Oct 2010. Canberra: ABS, 2011. (ABS Cat. No. 4704.0.)

4 Australian Bureau of Statistics. Australian Aboriginal and Torres Strait Islander health survey: first results, Australia, 2012-13. Canberra: ABS, 2013. (ABS Cat. No. 4727.0.55.001.)

5 Ivers R. Anti-tobacco programs for Aboriginal and Torres Strait Islander people 2011. Produced for the Closing the Gap Clearinghouse. Canberra: Australian Institute of Health and Welfare; and Melbourne: Australian Institute of Family Studies, 2011.

6 Lindorff KJ. Tobacco: time for action. National Aboriginal and Torres Strait Islander Tobacco Control Project. Final report. Canberra: National Aboriginal Community Controlled Health Organisation, 2002.

7 Johnston V, Thomas DP. Smoking behaviours in a remote Australian indigenous community: the influence of family and other factors. Soc Sci Med 2008; 67: 1708-1716.

8 Briggs VL, Lindorff KJ, Ivers RG. Aboriginal and Torres Strait Islander Australians and tobacco. Tob Control 2003; 12 Suppl 2: ii5-ii8.

9 Thomas D, Briggs V, Anderson IP, Cunningham J. The social determinants of being an Indigenous non-smoker. Aust NZ J Public Health 2008; 32: 110-116.

10 Paradies $Y$. A systematic review of empirical research on self-reported racism and health. Int J Epidemiol 2006; 35: 888-901.

11 Australian Bureau of Statistics. National Aboriginal and Torres Strait Islander Social Survey, 2008. Canberra: ABS, 2009. (ABS Cat. No. 4714.0.)

12 Hornik R, Woolf KD. Using cross-sectional surveys to plan message strategies. Soc Mar Q 1999; 5: 34-41.

13 Gould GS, Watt K, McEwen A, et al. Predictors of intentions to quit smoking in Aboriginal tobacco smokers of reproductive age in regional New South Wales (NSW), Australia: quantitative and qualitative findings of a cross-sectional survey. BMJ Open 2015; 5: e007020.

14 Gould GS, McEwen A, Watters T, et al. Should anti-tobacco media messages be culturally targeted for Indigenous populations? A systematic review and narrative synthesis. Tob Control 2013; 22: e7.

15 Thomas DP, Briggs VL, Couzos S, et al. Research methods of Talking About
The Smokes: an International Tobacco Control Policy Evaluation Project study with Aboriginal and Torres Strait Islander Australians. Med J Aust 2015; 202 (10 Suppl): S5-S12.

16 Couzos S, Nicholson AK, Hunt JM, et al. Talking About The Smokes: a large-scale, community-based participatory research project. Med J Aust 2015; 202 (10 Suppl): S13-S19.

17 StataCorp. Stata survey data reference manual: release 13. College Station, Tex: StataCorp, 2013. http://www.stata.com/ manualsl3/svy.pdf (accessed Apr 2015).

18 Robertson J, Conigrave K, Ivers R, et al. Addressing high rates of smoking in remote Aboriginal communities - new evidence for GPs. Aust Fam Physician 2013; 42: 492-496.

19 Bond C, Brough M, Spurling G, Hayman $\mathrm{N}$. "It had to be my choice": Indigenous smoking cessation and negotiations of risk, resistance and resilience. Health Risk Soc 2012; 14: 565-581.

20 Stead LF, Buitrago D, Preciado N, et al. Physician advice for smoking cessation. Cochrane Database Syst Rev 2013; (5): CD000165.

21 Durkin S, Brennan E, Wakefield M. Mass media campaigns to promote smoking cessation among adults: an integrative review. Tob Control 2012; 21: 127.

22 Stewart HS, Bowden JA, Bayly MC, et al. Potential effectiveness of specific antismoking mass media advertisements among Australian Indigenous smokers. Health Educ Res 2011; 26: 961-975.

23 Campbell MA, Finlay S, Lucas K, et al. Kick the habit: a social marketing campaign by Aboriginal communities in NSW. Aust $J$ Prim Health 2014; 20: 327-333.

24 Gould GS, Watt K, Stevenson L, et al. Developing anti-tobacco messages for Australian Aboriginal and Torres Strait Islander peoples: evidence from a national cross-sectional survey. BMC Public Health 2014; 14: 250.

25 Hornik RC, Ramirez AS. Racial/ethnic disparities and segmentation in communication campaigns. Am Behav Sci 2006; 49: 868-884.

26 Nicholson AK, Borland R, Couzos S, et al. Smoking-related knowledge and health risk beliefs in a national sample of Aboriginal and Torres Strait Islander people. Med J Aust 2015; 202 (10 Suppl): S45-S50.

27 Nicholson AK, Borland R, Sarin J, et al. Recall of anti-tobacco advertising and information, warning labels and news stories in a national sample of Aboriginal and Torres Strait Islander smokers. Med J Aust 2015; 202 (10 Suppl): S67-S72.
28 Gould GS, Munn J, Avuri S, et al. "Nobody smokes in the house if there's a new baby in it": Aboriginal perspectives on tobacco smoking in pregnancy and in the household in regional NSW Australia. Women Birth 2013; 26: 246-253.

29 Nicholson AK, Borland R, van der Sterren AE, et al. Social acceptability and desirability of smoking in a national sample of Aboriginal and Torres Strait Islander peoples. Med J Aust 2015; 202 (10 Suppl): S57-S62.

30 Fu SS, Rhodes KL, Robert C, et al. Designing and evaluating culturally specific smoking cessation interventions for American Indian communities. Nicotine Tob Res 2014; 16: 42-49.

31 Thomson G, Wilson N, Weerasekera D, Edwards R. Strong smoker interest in 'setting an example to children' by quitting: national survey data. Aust NZ J Public Health 2011; 35: 81-84.

32 Choi WS, Daley CM, James A, et al. Beliefs and attitudes regarding smoking cessation among American Indians: a pilot study. Ethn Dis 2006; 16: 35-40.

33 Herd N, Borland R, Hyland A. Predictors of smoking relapse by duration of abstinence: findings from the International Tobacco Control (ITC) Four Country Survey. Addiction 2009; 104: 2088-2099.

34 Hitchman SC, Fong GT, Zanna MP, et al. The relation between number of smoking friends, and quit intentions, attempts, and success: Findings from the International Tobacco Control (ITC) Four Country Survey. Psychol Addict Behav 2014; 28: 1144-1152.

35 Nicholson AK, Borland R, Davey ME, et al. Past quit attempts in a national sample of Aboriginal and Torres Strait Islander smokers. Med J Aust 2015; 202 (10 Suppl): S20-S25.

36 Thomas D. National trends in Aboriginal and Torres Strait Islander smoking and quitting, 1994-2008. Aust N Z J Public Health 2012; 36: 24-29.

37 Fidler J, Ferguson SG, Brown J, et al. How does rate of smoking cessation vary by age, gender and social grade? Findings from a population survey in England. Addiction 2013; 108: 1680-1685.

38 Smith PH, Kasza KA, Hyland A, et al. Gender differences in medication use and cigarette smoking cessation: results from the international tobacco control four country survey. Nicotine Tob Res 2015; 17: 463-472.

39 Siahpush M, McNeill A, Borland R, Fong GT. Socioeconomic variations in nicotine dependence, self-efficacy, and intention to quit across four countries: Findings from the International Tobacco Control 
(ITC) Four Country Survey. Tob Control 2006; 15 Suppl 3: iii7l-iii75.

40 Reid JL, Hammond D, Boudreau C, et al. Socioeconomic disparities in quit intentions, quit attempts, and smoking abstinence among smokers in four western countries: findings from the International Tobacco Control Four Country Survey. Nicotine Tob Res 2010; 12 Suppl: S20-S33.

41 Siahpush M, Borland R, Yong HH, et al. Tobacco expenditure, smoking-induced deprivation and financial stress: results from the International Tobacco Control (ITC) Four-Country Survey. Drug Alcohol Rev 2012; 31: 664-671.

42 Lawrence D, Hafekost J, Hull P, et al. Smoking, mental illness and socioeconomic disadvantage: analysis of the Australian National Survey of Mental Health and Wellbeing. BMC Public Health 2013; 13: 462-462.

43 Lawrence D, Mitrou F, Zubrick SR. Nonspecific psychological distress, smoking status and smoking cessation: United States National Health Interview Survey 2005. BMC Public Health 2011; 11: 256-268.

44 Twyman L, Bonevski B, Paul C, Bryant J. Perceived barriers to smoking cessation in selected vulnerable groups: a systematic review of the qualitative and quantitative literature. BMJ Open 2014; 4: e006414.

45 Nagelhout GE, Willemsen MC, Thompson ME, et al. Is web interviewing a good alternative to telephone interviewing? Findings from the International Tobacco Control (ITC) Netherlands Survey. BMC Public Health 2010; 10: 351-360.

46 Persoskie A, Nelson WL. Just blowing smoke? Social desirability and reporting of intentions to quit smoking. Nicotine Tob Res 2013; 15: 2088-2093.

47 International Agency for Research on Cancer. Developing and assessing comparable questions in cross-cultural survey research in tobacco. In: IARC handbooks of cancer prevention: tobacco control. Volume 12. Methods for evaluating tobacco control policies. Lyon: IARC, 2008: 59-74.

48 Borland R. The structure of the change process. In: Understanding hard to maintain behaviour change. Chichester: John Wiley \& Sons, 2014: 142-171.

49 Partos TR, Borland R, Yong HH, et al. The quitting rollercoaster: how recent quitting history affects future cessation outcomes. Nicotine Tob Res 2013; 15: 1578-1587.

50 Borland R, Yong $\mathrm{H}-\mathrm{H}$, Balmford J, et al. Motivational factors predict quit attempts but not maintenance of smoking cessation: findings from the International Tobacco Control Four country project. Nicotine Tob Res 2010; 12 Suppl: S4-S11.

51 Vangeli E, Stapleton J, Smit ES, et al. Predictors of attempts to stop smoking and their success in adult general population samples: a systematic review. Addiction 2011; 106: 2110-2121. •

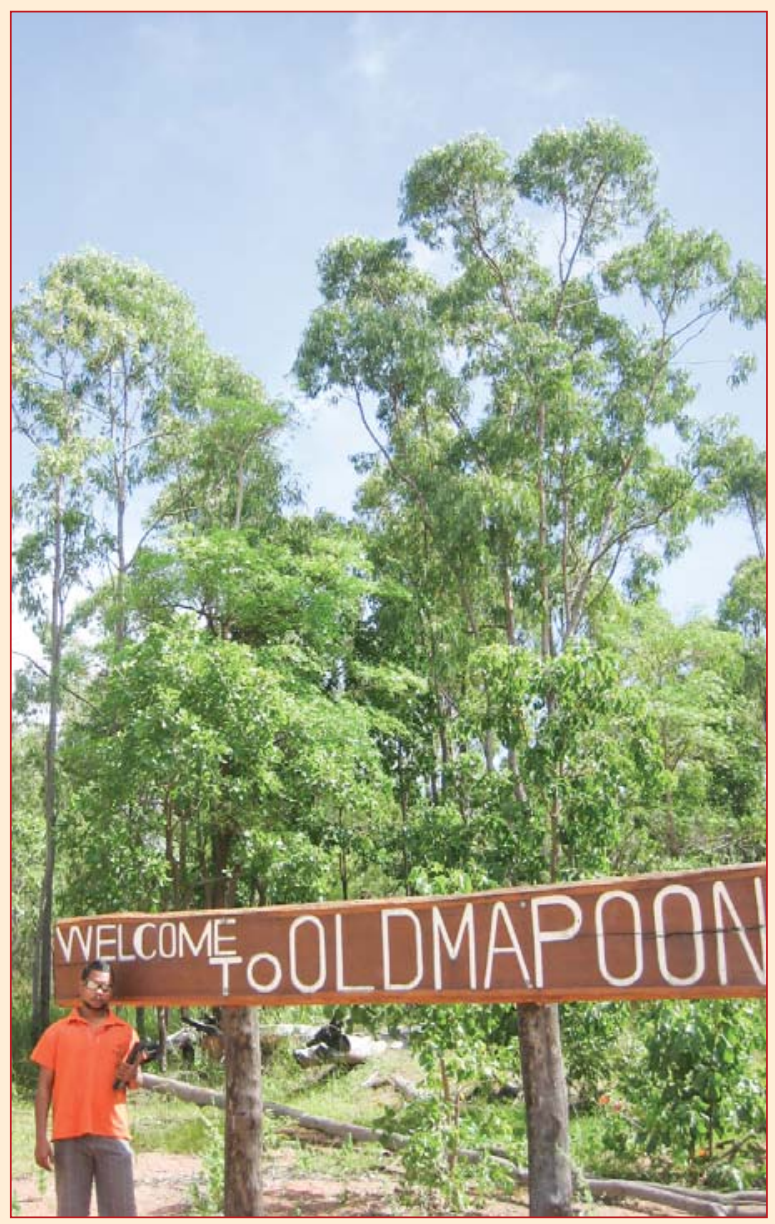

Local research assistant Kevin Manantan from Apunipima Cape York Health Council at Old Mapoon, Queensland.

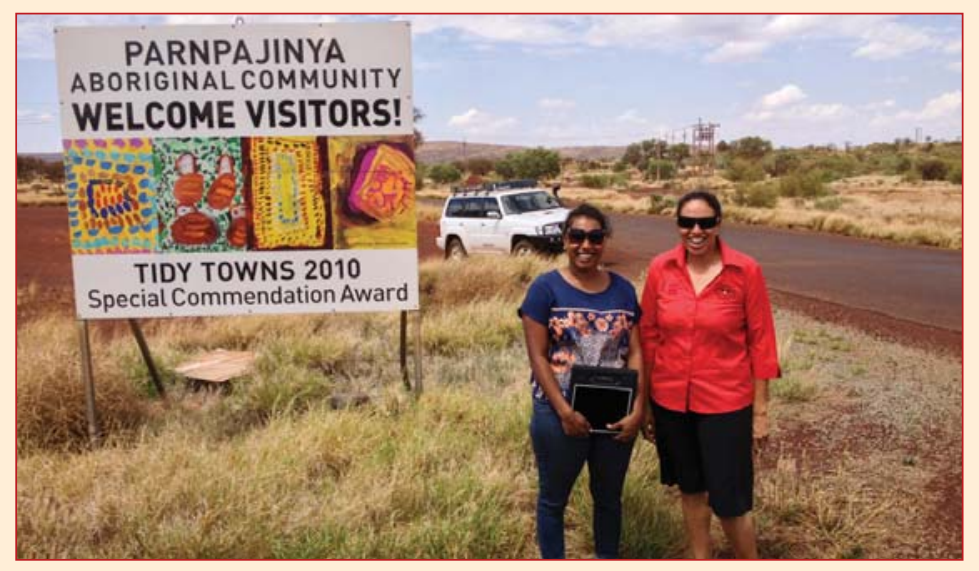

Local research assistants Bianca Turvey and Tina Ewan from Puntukurnu Aboriginal Medical Service, Western Australia.

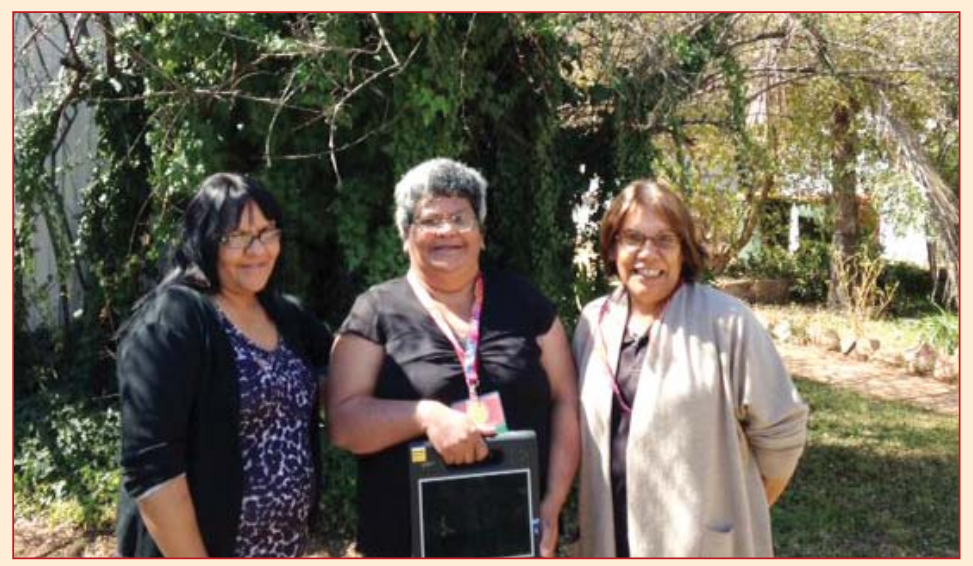

Peak Hill Aboriginal Medical Service, NSW, CEO Christine Peckham with local research assistants Bernadette Hazel and Sandra Peckham. 